\title{
Learning from Popular Culture: The "Politics" of Competitive Reality Television Programs
}

David R. Dreyer, Lenoir-Rhyne University

ABSTRACT Reality television programming has become a pervasive part of popular culture. Although such programming may seem to be mindless entertainment, it can serve as a tool to introduce political lessons in the classroom. This article examines how the concepts of alliance behavior and strategic voting can be explored by using the television program Survivor. An analysis reveals that contestants often behave strategically when forming alliances and voting, in ways that are similar to the strategic behavior of nation-states and individuals residing in democracies, respectively. This article does not suggest that reading political science texts should be replaced with viewing reality television, but rather that instructors can introduce abstract concepts to undergraduate students through popular culture. Such a technique can spark students' interest in politics and demonstrate the broad relevance of political concepts, leaving students with the desire to delve more deeply into the investigation of political phenomena.



egardless of how many academic books and journal articles are assigned in an undergraduate class in a given semester, some students will likely spend more time watching reality television than reading. Recent reality television shows include such programs as Rock of Love Bus, on which an aging rocker searches for "love" on an alcohol-fueled rock-and-roll tour, and Wife Swap, on which the mothers of two polar opposite families trade places, often resulting in cursing, temper tantrums, and mayhem. Educators may bemoan such programming and the priorities of some students who are more interested in the results of I Love Money than the results of the midterm congressional elections.

Taken at face value, not much can be learned from reality television. Lurking beneath the surface, however, are lessons about the political world. Most reality television shows involve strategic competition. In some such as Survivor and Big Brother, contestants are eliminated through the ballot box. Both shows generally involve individuals forming coalitions or alliances, campaigning, bargaining, and making decisions strategically. Casual viewers

David R. Dreyer is an assistant professor of political science at Lenoir-Rhyne University. His research interests include international conflict, interstate rivalry, and contentious issues. He can be reached at dreyerda@msu.edu. likely do not often make connections between the "politics" of reality television and the politics of national, state, and local government. By pointing out to students how political processes operate in reality television shows, however, it may be possible to turn otherwise mindless viewing into instructive learning and draw typically reluctant participants into class discussion.

This article examines two political phenomena-alliance behavior and strategic voting-and discusses how they can be introduced in the classroom through reference to popular culture. Once an instructor has caught the attention of his or her audience, he or she can then delve into the intricacies of academic arguments that reach far beyond what can be observed by watching the strategic interplay of reality television show contestants. Initially presenting material to undergraduate students in relation to something that is accessible and familiar, however, increases the likelihood that students will be interested in and willing to engage with course material.

\section{ALLIANCES: BALANCING POWER, BALANCING THREAT,} AND BANDWAGONING

Do states balance power, balance threat, or bandwagon? Such a question is likely addressed in most introductory courses on 
international relations and courses on international conflict. Although concepts such as balancing and bandwagoning are relatively straightforward, undergraduates may perceive some issues, such as the difference between balancing power and balancing threat, as academic posturing or mere semantics. Drawing on examples from popular culture may help illuminate differences between contending perspectives and demonstrate the underlying logic of competing explanations.

Tendencies toward balancing power are apparent in both domestic and international politics. As Hans Morgenthau (2006), the founding father of modern realism, argues, the design of the American political system, with its emphases on checks and balances and the preservation of equilibrium, is similar to the international system, in which states tend to balance power, thereby establishing equilibrium. A primary purpose of domestic checks and balances, like international balances, is to prevent any one actor from becoming too powerful. Such balances prevent despotism domestically and revisionism internationally.

Similar to classical realists such as Morgenthau, who wrote on the preservation of international balances of power, in the canonical text of structural realism, Theory of International Politics (1979), Kenneth Waltz posited that states tend to balance power. In the anarchic international system, a central authority that enforces rules and preserves peace is lacking. States must consequently provide for their own security. Because there is nothing to prevent a powerful state from overtaking weaker states, power disparities threaten the survival of less powerful states. Relatively weak states should consequently tend to seek to balance power.

Amending balance of power theory, Stephen Walt (1987) has argued that states balance against threats instead of power. Powerful states with aggressive intentions are threatening. Hegemonic states, however, do not necessarily have aggressive intentions. Instead, a dominant state may be isolationist in orientation and content with preserving the status quo rather than altering it by, for example, seeking territorial aggrandizement. Conversely, a relatively weak state may have aggressive intentions and actively seek to acquire territory, thereby constituting more of a threat than a more powerful, but isolationist state.

How can instructors introduce and differentiate the concepts of balancing power and balancing threat to students who may tune out once they hear a term such as "hegemon"? Although not generally employing such terms, reality television contestants at times consider balance of power and balance of threat strategies. Exploring their reliance on such strategies may help illuminate the similarities and differences between balancing power and balancing threat.

As in the international system, failure to balance power in competitive reality television shows may put one's survival at risk. For example, in Survivor, contestants engage in competitions in order to win rewards or immunity (i.e., protection against being voted "off the island"). Because such competitions are often physical in nature, strong and athletic contestants generally have an advantage. If unable to be stopped, a strong contestant can make it to the end of a game largely through his or her success in immunity challenges. In Survivor: Cook Islands, for example, athletic contestant Oscar "Ozzy" Lusth won six out of eight individual immunity challenges, including the last three, propelling himself to the final round. Similarly, in Survivor: The Australian Outback, physically fit contestant Colby Donaldson took himself to the final round by winning the last five immunity challenges.
Physically strong and athletic contestants may consequently become the target of balancers. For example, after winning two immunity challenges in a row in Survivor: Tocantins, contestant Tyson Apostal had proven himself a strong physical competitor. After losing the next immunity challenge, some of the other competitors decided to take the opportunity presented by the next vote to balance power before it became too late. As contestant Steven Fishbach stated in episode ten, "I think we might just take out Tyson. We might not get another chance.... If we don't take out Tyson right now, he could go on a run. It happens every season, someone goes on a run."

Yet Survivor is not strictly a physical competition. The game also has a social component. Being well liked and "friends" with other contestants can help one advance far, even to the point of winning. In Survivor: The Australian Outback, Colby Donaldson's physical prowess outmatched that of Tina Wesson, whom he defeated in the last five challenges. Yet Tina, who was generally well liked, made it to the final round and ultimately walked away with the one million dollar prize. Although balancing against power earlier in the game would have prevented Colby from progressing to the final round, in order for a different contestant to win, the players would have ultimately needed to balance against Tina, who was the inferior physical competitor but more "threatening" as a result of her personal appeal.

Contestants may thus seek to balance against threats instead of power. When contestants returned to compete in Survivor: AllStars, they quickly balanced against threat and voted Tina off the island in the first round. Stronger physical competitors were present, such as Tina's previous adversary and proven immunity challenge winner Colby. The contestants first, however, chose to balance against threat, only later balancing against power in the seventh episode, when they finally voted Colby out of the game.

Despite differences between balancing power and balancing threat, both strategies are similar in that one aligns against others who can potentially do the most harm. But besides balancing power and balancing threat, a third behavior can occur: bandwagoning, or aligning with superior power. States may bandwagon for several reasons, such as, in order to reap the "fruits of victory" after war or to ride the "wave of the future." Schweller (1994) argues that although international relations scholars generally assume that states balance against power or threat, policymakers often assume that states tend to bandwagon. The decision to go to war in Vietnam, for example, was based in part on "domino theory" in which it was believed that if Vietnam fell to communism, other states in the region would as well.

Just as they consider adopting balancing power or balancing threat strategies, reality show contestants also at times consider bandwagoning. Survivorgenerally begins with separate tribes competing for rewards and immunity. At this stage, contestants often view the optimal strategy for winning challenges to be bandwagoning with the strongest players in one's tribe. In this way, weaker players can ride the coattails of stronger players and enjoy rewards such as matches for fire, food, drinks, or immunity from being voted off the island. As mentioned previously, contestants on Survivor: All-Stars did not initially balance against strong physical competitor Colby Donaldson, making it such that the tribe increased its chances to win reward and immunity challenges against the other tribes.

A bandwagoning strategy, however, can potentially backfire in the long run. In the international system, if a state chooses to 
ally with a stronger state rather than balance against power, the stronger state may become even more powerful and eventually turn on its allies. Given that "friends today can be enemies tomorrow," the weaker state may ultimately regret its decision to not attempt to balance power before the stronger state further increased its strength.

Just as bandwagoning can backfire in the international sphere, it can also backfire in the realm of reality television competitions. In Survivor, once the game progresses to the "merge," in which separate tribes consolidate into one and as numbers begin to dwindle, weaker players may wish that they had voted off stronger players earlier, when they had the opportunity. The Survivor: AllStars competitors were careful to avoid this outcome, despite an the other. If only a single party exists on the right of the ideological spectrum, that party will likely receive most of the votes from right-leaning individuals. If the votes of individuals with leftist ideological orientations are split between the two candidates on the left and individuals with rightist ideological orientations vote for the candidate on the right, assuming that voters are ideologically evenly distributed, the candidate on the right will win.

Two parties on one side of the ideological spectrum consequently have an incentive to form a coalition. Moreover, once dominant parties on the right and left are established, potential political candidates have an incentive to seek a major party nomination rather than the nomination of a third party, which is likely to receive

\section{Just as they consider adopting balancing power or balancing threat strategies, reality show contestants also at times consider bandwagoning. Survivor generally begins with separate tribes competing for rewards and immunity. At this stage, contestants often view the optimal strategy for winning challenges to be bandwagoning with the strongest players in one's tribe. In this way, weaker players can ride the coattails of stronger players and enjoy rewards such as matches for fire, food, drinks, or immunity from being voted off the island.}

initial strategy of bandwagoning with strong contestants like Colby. Although the players kept Colby in the competition at first to reap the benefits of winning challenges, they voted him out prior to the merge to prevent him from winning individual immunity challenges and advancing to the final round.

Because of the prevalence of consideration concerning whether to balance power, balance threat, or bandwagon in Survivor, referencing the show in the classroom may be a good way to introduce such concepts to students in a way that is accessible and familiar. Along with decisions concerning alliance formation, contestants on some reality television programs must make decisions concerning voting. Similar to discussing alliance behavior, a discussion of the voting decisions made on such shows can help illuminate how and why voters make strategic decisions when it comes to ballot box behavior.

\section{DUVERGER'S LAW}

Very few theories in the social sciences are considered "laws." The finding that single-member-district plurality electoral systems tend to produce two-party systems (Duverger 1963) while proportional representation systems tend to produce multiparty systems is one of the few empirical findings in political science that has been granted lawlike status. Discussion of Duverger's Law is relevant to comparative politics courses to explain variation in party systems and American politics courses to explain why the United States has two dominant political parties.

Single-member-district plurality systems tend to produce twoparty systems as a result of the strategic behavior of political elites and individual voters in the mass public. In relation to the behavior of political elites, potential contenders for political office may form informal or formal coalitions to prevent "splitting the vote." For example, if two parties exist on the left of the ideological spectrum and both parties field candidates, some leftleaning voters may vote for one party while others may vote for only a small percentage of the vote. The behavior of political elites thus contributes to the development of a two-party system in states with single-member-district plurality electoral rules.

Voters in the mass public also behave strategically. Voting for a minor party candidate in single-member-district plurality electoral systems is at times considered to be "wasting one's vote" since the candidate has little chance of winning. Even if an individual is relatively dissatisfied with the two major party competitors, he or she can at least choose the lesser of two evils, rather than vote for a candidate who is destined to lose. This differs from states with proportional representation electoral systems, in which a party's representation in the legislature is roughly equivalent to the percentage of the vote that it receives, making it such that minor parties can gain some representation in the legislature and it is therefore not "wasting one's vote" to cast a ballot for a minor party.

The end result of such strategic interplay in states with singlemember-district plurality systems tends to be the emergence of a two-party system. Political candidates form coalitions and often seek a major party nomination, while voters generally choose between candidates from the dominant political parties. Known as Duverger's Law, this is one of the most significant ways that electoral institutions affect political outcomes.

The voting system of a competitive reality television program such as Survivor differs from real world politics in that there are fewer participants, the potential benefits of voting are much higher (a contestant can win one million dollars), a contestant is not voting for someone to represent him or herself, and individuals vote against instead of for someone. Nevertheless, "tribal council" votes resemble single-member-district plurality voting in that the single contestant who receives a plurality of votes is kicked off the island. As a consequence, players on the show behave similarly in some ways to political actors and voters in single-memberdistrict plurality systems. 
Leading up to a tribal council vote in Survivor, two coalitions generally solidify, each of which target an individual for possible elimination. An individual player may prefer that a different contestant than either of the two being considered for expulsion be eliminated. Players generally do not "waste votes," however, on candidates for which others are not planning on voting; instead, they will generally choose to vote for expelling the "greater of two evils."

In the first season of Survivor, contestant Susan Hawk expressed what has perhaps been the most vehement hatred ever shown toward another contestant on the show, telling Kelly Wiglesworth, "If I would ever pass you along in life and you are laying there dying of thirst, I would not give you a drink of water. I would let the vultures take you and do whatever they want with you no ill regrets." Despite such extreme abhorrence, Susan did not once cast an elimination vote for Kelly in the game, even though she participated in ten tribal council votes in which voting for Kelly was an option. Instead, in every vote, Susan voted for one of the top two vote-receivers.

With four contestants, including Susan and Kelly, remaining in the game, Susan had the option to vote for Kelly, Rudy Boesch, or Richard Hatch. Although Susan disliked both Kelly and Richard, in the final episode, she stated that she disliked Kelly more and preferred that Richard win the game. If Susan had voted purely on the basis of her preferences during the "final four" vote, she would have voted against Kelly. Instead, however, she voted for Richard to be expelled from the game. Because Kelly voted for Richard, a vote from Susan for Kelly would have split their votes, leaving the other two contestants with a plurality of votes necessary to eliminate Susan. Instead, with Rudy and Richard voting for Susan and Kelly voting for Richard, Susan was able to force a tie between herself and Richard by voting for Richard. Susan chose this option over "wasting her vote" on her first preference, Kelly, and losing in a 2-1-1 vote.

Table 1 shows the sum of the number of votes cast for the two top vote-receivers for each tribal council in relation to the total number of votes cast in each season of Survivor. For example, in Season 18, 93.4\% of all votes were cast for one of two contestants who were being considered by the two primary coalitions for elimination at a tribal council. Less than $7 \%$ of all the votes, in other words, were wasted on contestants who had little chance of being eliminated. Overall, the data indicate that strategic behavior is extremely common on Survivor. In all seasons of Survivor combined, $96.7 \%$ of all votes have been cast for one of two "parties." Very few individual votes have been "wasted."

The lowest rate of strategic behavior exhibited in a season occurred in Season 1, in which 90.1\% of the votes were cast for the top two vote-receivers. Although this percentage is itself high, contestants in subsequent seasons seemed to have learned to behave more strategically. Data from Survivor: All-Stars (Season 8) indicate that the show's veterans did, in fact, behave like "allstars" when it came to voting contestants off the island. During the entire season, not one vote was cast for someone other than the top two vote-receivers in a tribal council vote.

The coalitions that form in Survivor may be ad hoc arrangements constructed leading up to a vote or more stable coalitions that last throughout several votes. Either way, contestants in each coalition generally target a single individual and avoid splitting the vote on multiple opponents. In this way, no votes are wasted
Table 1

\section{"Two Party" Voting among Survivor Contestants, by Season}

\begin{tabular}{lccc} 
SEASON & $\begin{array}{c}\text { TWO-PARTY } \\
\text { VOTES }\end{array}$ & $\begin{array}{c}\text { TOTAL VOTES } \\
\text { CAST }\end{array}$ & $\begin{array}{c}\text { \% OF TWO-PARTY } \\
\text { VOTES }\end{array}$ \\
\hline 1 & 82 & 91 & 90.1 \\
\hline 2 & 83 & 85 & 97.6 \\
\hline 3 & 91 & 91 & 100.0 \\
\hline 4 & 85 & 87 & 97.7 \\
\hline 5 & 79 & 81 & 97.5 \\
\hline 6 & 87 & 91 & 95.6 \\
\hline 7 & 94 & 95 & 98.9 \\
\hline 8 & 78 & 78 & 100.0 \\
\hline 9 & 107 & 109 & 98.2 \\
\hline 10 & 78 & 82 & 95.1 \\
\hline 11 & 107 & 108 & 99.1 \\
\hline 12 & 73 & 77 & 94.8 \\
\hline 13 & 115 & 116 & 99.1 \\
\hline 14 & 95 & 101 & 94.1 \\
\hline 15 & 86 & 90 & 95.6 \\
\hline 16 & 102 & 106 & 96.2 \\
\hline 17 & 102 & 102 & 100.0 \\
\hline 18 & 75 & 80 & 93.4 \\
\hline Total & $\mathbf{1 0 6 7 0}$ & \\
\hline & & & 96.9 \\
\hline
\end{tabular}

Note: Numbers and percentages exclude final votes in which there are only two contestants left to choose from, and second-to-last votes in which the winner of the immunity challenge selects the one contestant that they would like to take with them to the finale.

on individuals who are unlikely to be eliminated, and the larger coalition generally prevails over the smaller coalition.

\section{CONCLUSION}

Reality television has become a central component of American popular culture. Every year, millions tune in to watch competitive reality shows in which contestants compete for love or money. Such shows have infiltrated the airwaves, offering viewers another option besides more traditional programs such as sitcoms and drama miniseries.

In this article, I argue that instructors can draw classroom lessons from competitive reality television programs by showing ways in which contestants engage in strategic behavior. Phenomena such as balancing power, balancing threat, and bandwagoning, for example, can be explained in relation to the show Survivor. Furthermore, since voting determines who progresses in Survivor, the dynamics of strategic voting can be illuminated in reference to the show.

There are additional political concepts that can be introduced in the classroom through reference to reality television show programming. Instructors may reference Wife Swap, for example, to explain the concept of polarizing cleavages and illustrate the potential consequences of placing individuals with diametrically opposed viewpoints in close proximity. The prisoner's dilemma 
and the importance of trust in establishing cooperation could also be discussed in relation to competitive reality programs such as Survivor.

I am not suggesting that the reading of academic texts should be replaced with television viewing. Nor do I believe that students can learn everything they need to know about politics through watching reality shows. Nonetheless, popular culture can at times be referenced in discussions of course material, providing students with alternative ways to think about certain concepts, thereby facilitating learning.

It is unrealistic to expect that every student in an introductory class, particularly those who are not political science majors, will find debates over such concepts as whether states balance power, balance threat, or bandwagon to be inherently interesting. If we can demonstrate, however, that such issues have a wider relevance that reaches beyond the halls of academia, students may find such debates more interesting and pertinent. Moreover, the next time a student watches Survivor or another competitive reality show, he or she may find him or herself pondering whether actors tend to balance power, balance threats, or bandwagon in political and social situations. Demonstrating the broad relevance of important concepts can provide students with theoretical road maps on which they can rely to think critically about problems and issues that may arise in any line of work that they choose to pursue after the completion of their degree.

\section{REFERENCES}

Duverger, Maurice. 1963. Political Parties: Their Organization and Activity in the Modern State, trans. Barbara North and Robert North. New York: John Wiley and Sons.

Morgenthau, Hans. 2006. Politics among Nations: The Struggle for Power and Peace. 7 th ed. New York: Random House.

Schweller, Randall L. 1994. "Bandwagoning for Profit: Bringing the Revisionist State Back In.” International Security 19 (1): 72-107.

Walt, Stephen M. 1987. The Origins of Alliances. Ithaca, NY: Cornell University Press.

Waltz, Kenneth. 1979. Theory of International Politics. New York: McGraw-Hill. 


\section{CAMBRIDGE}

\section{JOURNALS}

\section{The Journal of Politics}

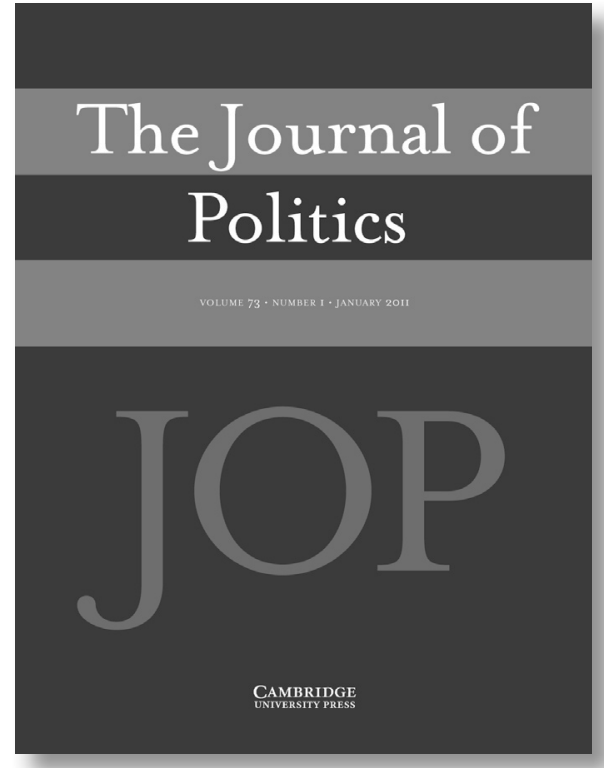

Editors:

Jan E. Leighley, American University

William Mishler, University of Arizona

The Journal of Politics is a leading general journal of political science which publishes path-breaking research in all subfields from all parts of the world including, but not limited to, American politics; comparative politics; formal theory; international relations; methodology; political theory; public administration; and public policy.

\section{Published for the Southern Political Science Association}

FRE email alerts. Keep up-to-date with new material. Sign up at: journals.cambridge.org/jop-alerts

\section{journals.cambridge.org/jop}

Recommend

The Journal of Politics directly from its homepage FREE online access for you when your library subscribes. 